\title{
EL PROBLEMA DE LA ENUNCIACION DEL YO LIRICO EN EL "BEATUS ILLE" DE QUINTO HORACIO FLACO
}

Gladys Alicia Miranda Hevia

\section{INTRODUCCION}

Este trabajo surgió de una traducción al español del "Beatus ille" de Quinto Horacio Flaco. La lenta labor de conversión de una lengua a otra hizo que se planteara una pregunta sobre las dos últimas estrofas del poema. Se intentó averiguar si eran realmente necesarias; y en caso que lo fueran, se quiso determinar sus posibles funciones. Estos fueron los objetivos de la investigación.

El original ha sido elaborado varias veces hasta adquirir la forma que ahora tiene. Para su publicación se eliminó la traducción española puesto que el trabajo se basa en el texto latino. Se mantiene esencialmente el análisis, pero se han omitido algunas observaciones y gran parte de las concl usiones. Hay que disculpar lo que conserva de torpe nomenclatura y esquemático lenguaje.

Debo agradecer la valiosa cooperación del profesor Víctor Sánchez y las amables observaciones de la Dra. Clara Corneli, así como la aprobación del director de la Escuela de Filología, Dr. Jézer González. Los apuntes de las lecciones de la Lic. Virginia Sandoval de Fonseca proporcionaron el mé todo de análisis que se utilizó.

Gladys Alicia Miranda Hevia Agosto de 1975 Flaco.

El problema de la enunciación del yo lírico en el "Beatus ille" de Quinto Horacio

I. el elemento sonoro

a. la métrica 
El épodo que nos ocupa consta de setenta versos ordenados en 35 pares o estrofas. Cada una está compuesta por un yámbico senario y un yámbico cuaternario. Estos versos reciben también el nombre de trímetro y dímetro yámbicos respectivamente. El esquema formal es el siguiente:

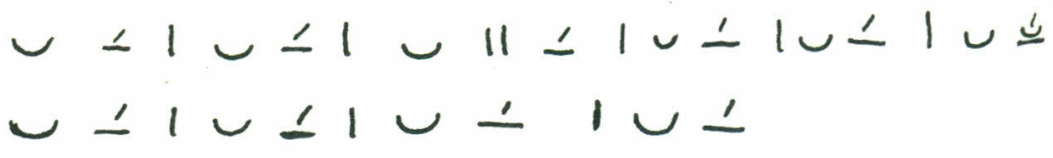
métrico:

Las primeras cuatro estrofas del poema permiten apreciar claramente el esquema

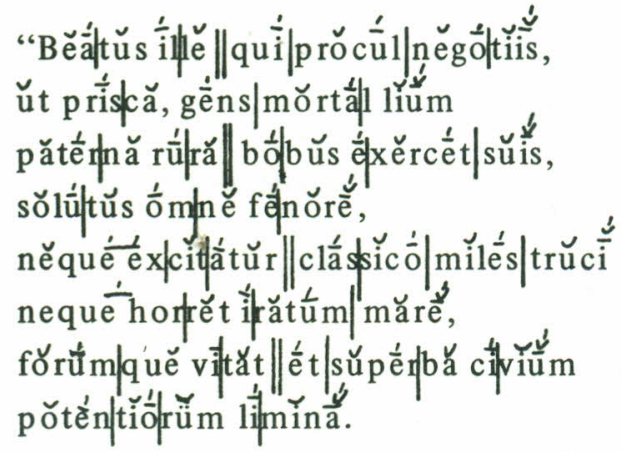

\section{b. El ritmo}

Hay diversidad de criterios en torno al ritmo lírico. Por una parte Kayser ${ }^{1}$ se refiere únicamente al ritmo de las lenguas románicas y germánicas. Se abstiene, además, de presentar una definición concretá del fenómeno y lo considera una entidad separada de la métrica.

Wellek y Warren ${ }^{2}$ dividen las teorías sobre el ritmo en dos grupos. El primero estaría formado por las teorías que exigen periocidad como requisito indispensable del ritmo. En el segundo grupo se encuentran aquellas teorías para las cuales la periodicidad no es el fundamento del ritmo.

Se podría colocar el pensamiento de Kayser en el primer grupo. Según este autor, el ritmo sólo vive en las palabras ${ }^{3}$ y el ritmo es diferente en cada poema.

Por lo común se opina que el sistema rítmico de la poesía horaciana y en general de la grecolatina se basa en la duración de las sílabas, no en la acentuación ni en las semejanzas fónicas. Puede hacerse un análisis del ritmo de este poema con base en dos elementos: a.- el estrato temporal, y, b.- la importancia de ciertos elementos fónicos (sílabas largas) en este estrato.

Las sílabas largas duran dos moras, o sea, dos unidades de tiempo. Las sílabas breves duran una mora. Podrían representarse respectivamente como 2 y 1 . Si aplicamos estos símbolos al esquema métrico del épodo tenemos:

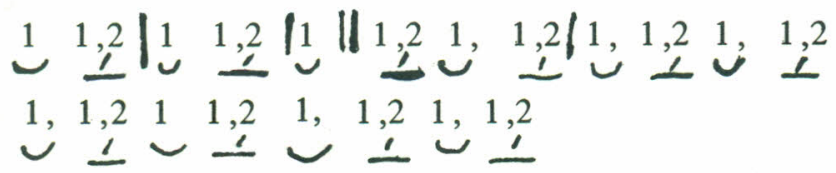


y al separar el esquema rítmico del métrico:

$$
\begin{array}{lll|lll|l|lllllll|lll|lll}
1 & 1 & 2 & 1 & 1 & 2 & 1 & || & 1 & 2 & \mid & 1 & 1 & 2 & 1 & 1 & 2 & 1 & 1 & 2 \\
1 & 1 & 2 & 1 & 1 & 2 & 1 & 1 & 2 & \mid & 1 & 1 & 2 & & & & & &
\end{array}
$$

Cada pie tiene tres moras, una de la sílaba breve y dos de la sílaba larga. Se contituye un ritmo de tres -así llanado en música-cuando se repite el patrón temporal 1112 . En música, los patrones rítmicos son muy rigurosos, pero no lo son tanto en poesía. Además, entra en juego la variable semántica, pues las palabras no son únicamente sonido. Se puede, sin embargo, llamar ritmo de tres al ritmo de este poema.

El primer verso de cada estrofa presenta una cesura, por lo que las moras quedan distribuidas así:

$$
\text { 1a 2a } 3 \text { a|4a 5a6a|7all8a9al 10a 11a12a|13a 14a15a|16a 17a18a }
$$

Interesa en gran manera analizar la distribución de las moras, sobre todo en los primeros versos. Hay que atender especialmente a la sétima mora de cada pie y al grupo formado por la octava y novena moras, que comienzan el segundo grupo rítmico del senario.

Observemos con este propósito las dos primeras y las dos últimas estrofas del poema:

1 Beatus ille qui procul negotiis ut prisca gens mortalium

3 paterna rura bobus exert suis solutus omni fenore...

67 Haec ubi locutus fenerator Alfius, iam iam futurus rusticus,

69 omnem redegit Idibus pecuniam, quaerit Kalendis ponere.

En el primer verso, la sétima mora se ubica en la última vocal de "ille". Por medio del ritmo se ha hecho énfasis en la deixis de lejanía del pronombre. La octava y novena moras refuerzan el "qui", relativo que explica el significado de "beatus". En el verso 67, el refuerzo de la cesura recae en "locutus"; y en el verso 69, en "redegit". Con base en la observación de estas dos estrofas, se puede esquematizar la organización del poema en la siguiente forma:

\section{Alfius locutus: Beatus ille...Lares}

$\begin{array}{cc}- & + \\ \text { negativo } & \text { positivo }\end{array}$

Este esbozo nos será útil más adelante. Por la extensión del poema no hemos analizado todo en cuanto al ritmo se refiere, ni tampoco los cambios de ritmo por sustitución de pies. Tal estudio, forzasamente más profundo y especializado, podría revelar interesantes conclusiones, pero sería el tema de otra investigación.

c.

La sonoridad

Es el empleo de sonidos especiales de la lengua para producir algún efecto. Está indisolublemente ligado al contexto semántico. No se va a analizar todo el poema, sino algunos usos notables del sonido en partes de éste.

1. "...neque horret iratum mare..." (v.6)

Nótese el contexto semántico de este verso: el "ille" a que se refiere no debe temer al 
mar, precisamente porque se ha retirado de la vida pública, una de cuyas faces es el comercio. Quien comercia sí debe enfrentarse al mar y sobre todo a las tormentas. Aquí se refuerza la descripción con el empleo de léxico: "horret", "iratum", y por medio de sonidos: q, rr, r, t, la nasal m, además del fuerte sonido final de "iratum".

2. "...aut in reducta valle mugientium

prospectact errantis greges..." (vv. 11 y 12)

Encontramos un caso de onomatopeya en "mugientium", que reproduce el sonido del mugir de las vacas y aquí está reduplicado: "mugientium".

3. "Labuntur altis interim ripis aquae, queruntur in silvis aves, fontesque lymphis obstrepunt manantibus somnos quod invitet leves”. (vv.25, 26, 27 y 28)

Este es un caso notable del empleo de la sonoridad en el poema. Puede verse confirmada la observación de que la sonoridad no puede separarse del contexto semántico. En estos cuatro versos y en los dos precedentes se describe un lugar ameno que consta de los siguientes elementos: árboles, prado, fuentes, aguas cristalinas, aves que cantan. No aparecen ni colorido violento ni movimiento rápido. Los contenidos semánticos del lugar ameno pueden esquematizarse así:

espaciales son dos y pueden reducirse a una ("iacere in gramine sub ilice"), las descripciones de sonido

\section{LOCUS AMOENUS}

\begin{tabular}{|c|c|c|l|}
\hline Localización espacial & $\begin{array}{l}\text { Localización } \\
\text { Temporal }\end{array}$ & $\begin{array}{l}\text { Descripción } \\
\text { del sonido }\end{array}$ & Efecto \\
\hline iacere sub ilice \\
in gramine & interim & $\begin{array}{l}\text { aquae labuntur } \\
\text { aves queruntur } \\
\text { fontes abstrepunt }\end{array}$ & $\begin{array}{l}\text { quod somnos } \\
\text { invitet leves }\end{array}$ \\
\hline
\end{tabular}

En los significados mismo el sonido desempeña una importante función. Mientras las localizaciones espaciales son dos y pueden redurcirse a una ("iacere in gramine sub ilice"), las descripciones de sonido son tres, constan de tres verbos y están bien diferenciadas. Se trata de producir en el estrato de la sonoridad todos los sonidos descritos en los contenidos semánticos del lugar ameno. Tenemos entonces el predominio de dos vocales, "u" e "i":

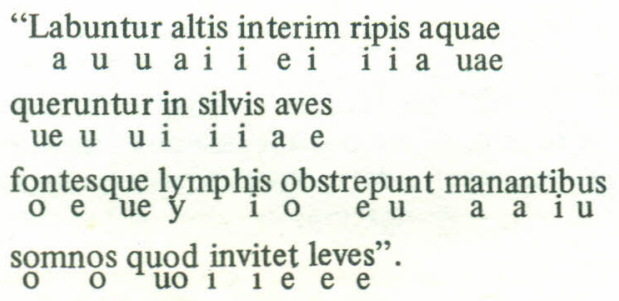

De esta observación de las vocales se deduce que en el poema no se reproduce el sonido mecánicamente, como en una grabación. El empleo acertado de las vocales hace más musicales los versos analizados y sostiene con el sonido mismo la descripción lírica del sonido. 
Obsérvese además en los versos anteriores la abundancia de los siguientes grupos, formados por una vocal y una consonante nasal: un, in, im, on, an, om. Son trece en total. Además se obtiene un efecto sonoro notable con la repetición de sonidos "unt" en "labuntur", "queruntur", obstrepunt".

\section{d. Las aliteraciones}

Podemos distinguir algunas aliteraciones a lo largo del poema. También pertenecen al estrato de la sunoridad. Se agrupan así:

\begin{tabular}{|c|c|c|}
\hline 1. . & Conjunción: & $\begin{array}{l}\text { "nec excitatur.... } \\
\text {...nec horret..." (vv. } 5 \text { y } 6 \text { ) }\end{array}$ \\
\hline 2. & Conjunción: & $\begin{array}{l}\text { "Ergo aut... } \\
\text { aut in reducta... } \\
\text { aut pressa puris mella... } \\
\text { aut tondit..." (vv.9 a 16) }\end{array}$ \\
\hline 3. & Conjunción: & $\begin{array}{l}\text { "Aut tradit...hinc et hinc... } \\
\text { aut amite levi..." (vv. } 29 \text { a 33) }\end{array}$ \\
\hline 4. & Adverbio: & $\begin{array}{l}\text { "NonAfra avis... } \\
\text { Non attagen Ionicus..." (vv. } 29 \text { a 33) }\end{array}$ \\
\hline 5. & Infinitivo: & $\begin{array}{l}\text { "Videre properantes... } \\
\text { Videre fessos..." (vv. } 62 \text { y } 63)\end{array}$ \\
\hline
\end{tabular}

Tres aliteraciones son de conjunciones, una de adverbio y una de infinitivo. Como hemos visto ya, a través del poema se reproduce un mundo hipotético- es decir, un mundo que podría ser y quien se encarga de describirlo es Alfius. La esencia del mundo poético construido está en el largo discurso de Alfius. El mundo puede cambiar según lo que haga este importante "ille' a que se refiere Alfius.

Estas aliteraciones tienen pues importancia en tanto que introducen disyunciones hipotéticas: presentan varias posibilidades dentro de la construcción de ese mundo hipotético que es el poema. Por ejemplo, en el fragmento de los vv. 9 a 16 podemos señalar la siguiente estructura gramatical:

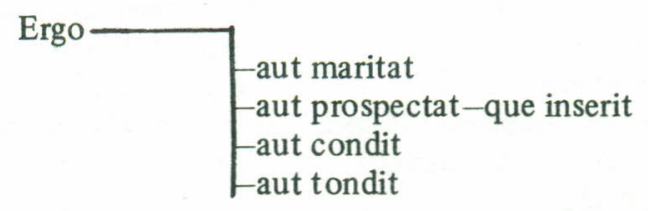

Este ergo introduce una oposición a los repetidos "ne" anteriores (vv. 5 y 6). La aliteración de "aut" (guiándonos siempre por la estructura gramatical) sirve por lo tanto para establecer una oposición con la posibilidad introducida por "ne": "nec excitatur...", "nec horret...".

En los versos anteriores se describe una posibilidad, un aspecto del mundo poético posible, que es real en tanto que pertenece a lo negado en su conjunto por Alfius, es decir, la realidad poética negativa. Al enunciar su discurso, Alfius parte de una realidad (que nosotros 
hemos convenido en llamar realidad poética negativa). Pero en el discurso de Alfius se construye una realidad diferente, que, además de ser hipotética, se constituye en la negación de la realidad que efectivamente y en el momento de la enunciación rodea a Alfius. Es la realidad del Beatus ille y hemos convenido en llamarla realidad poética positiva.

La posibilidad introducida por "ergo" no es real, es hipotética. Pero dentro del mundo configurado por el discurso de Alfius, en el cual actúa el Beatus ille., la única posibilidad que adquiere realidad poética-sea, una configuración por medio de las palabras-es la que está introducida por "ergo".

La aliteración de "aut" sirve, en este caso, para introducir disyunciones, variantes o ampliaciones del mundo de actividades del Beatus ille. En el poema este mundo es lo real.

Todas las actividades descritas en las oraciones introducidas por "aut" podrían cumplirse. En el mundo poético, son más reales que aquellas precedidas por "ne". Estas posibilidades descritas cumplen la función de integrar al mundo poético mismo. En éste se da su descripción, no su verificación. Por medio de la descripción, las hipotéticas actividades del Beatus ille pasan a ser aún más reales que las circunstancia de Alfius.

Repetimos que se toma como realidad poética negativa aquella que está introducida por ne. En esa realidad enuncia Alfius su discurso. Por otra parte, tenemos una realidad poética positiva, introducida por "aut", que constituye el mundo de las actividades del Beatus ille.

Se había señalado con anterioridad un esquema de la organización del poema. Con las observaciones hechas podemos señalar ya un proceso lírico de enunciación y distinguir un "él" lírico que enuncia (Alfius) y un objeto lírico que es enunciado ("Beatus ille qui...Lares). Se amplía el esquema en la siguiente forma:

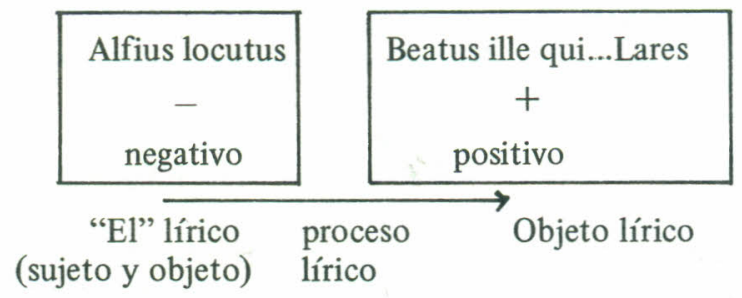

De acuerdo con la organización del poema, vemos que las aliteraciones se insertan dentro de la realidad poética positiva ("Beatus ille... Lares"). Esta se opone en forma absoluta con la realidad de Alfius, representada con signo negativo. Es aquí donde las aliteraciones adquieren carácter significativo.

\section{La estructura formal}

La organización de un poema por estrofas tiene como propósito reiterar la expresión lírica. En este poema sólo las dos últimas estrofas pertenecen al "yo" lírico propiamente tal (además de una posible intervención en la estrofa 19). Las primeras 33 estrofas pertenecen a la enunciación de Alfius, sea, en "él” lírico ya señalado.

La división constante por estrofas tan pequeñas en un poema de tal extensión pareciera señalar hacia una conjunción indivisible y no fortuita con el ritmo yámbico de compases cortos (con ciertas excepciones, vg. v.35).

En el estrato semántico se observa también la sucesión regular de pequeña extensión. Predomina sin ser absoluta, una relación biunívoca: imagen corta/ estrofa corta, que se analizará más adelante.

\section{La construcción del lenguaje}

La peculiaridad sintáctica más importante parece ser el uso de conjunciones, especialmente las disyuntivas. El inventario de estas formas gramaticales revela lo siguiente: 


\section{CONJUNCIONES COORDINANTES}

-copulativas: vv. $5,6,7,13,20,21,27,30,35,40,45,47,57,65$.

-disyuntivas: vv. $9,11,15,16,31,33,41,50,57,59,60$.

-adversativas: vv. 29, 39.

conclusivas: v. 9 .

\section{CONJUNCIONES SUBORDINANTES}

-comparativas: v. 2 .

-condicionales: vv. 39,51 .

-temporales: vv. 17, 29.

La mayoría de las conjunciones son copulativas y disyuntivas. Las primeras tienen como función coordinar: vinculan oraciones en el mismo nivel sintáctico. Las segundas también cumplen la función de coordinar. Sin embargo, las oraciones vinculadas por medio de disyuntivas ocupan planos diferentes desde el punto de vista semántico.

\section{ACTIVIDADES AGRICOLAS 1) Beatus ille qui exercet=nec excitatur=horret=vitat}

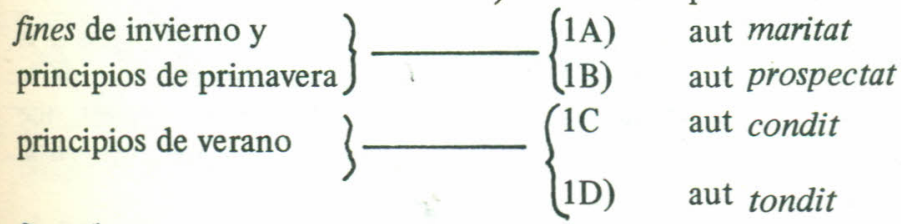

fines de verano y

principios de otoño

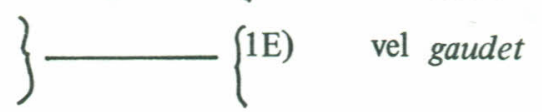

\section{ACTIVIDADES RECREATIVAS}

2) Libet iacere=labuntur $=$ queruntur $=$ obstrepunt - invitet 2a) aut trudit

2B) aut tendit=captat

3) Obliviscitur

4) Iuvet

4A) exstruat $=$ siccet $=$ appare $=$ iuverin $=$ descendat

5) Iuvat=videre $=$ videre

Mientras la cópula aparece en todos los planos de la acción en general, la disyunción aparece cuando se trata de ampliar la descripción del mundo poético.

A la acción inicial, 1), siguen las repetidas disyunciones que ofrecen alternativas: 1A), 1B), etc. Desde el punto de vista semántico, estas alternativas se refieren a actividades agrícolas, escalonadas según la cronología del trabajo campestre, en los climas de cuatro estaciones.

El segundo grupo de oraciones (2), se refiere a actividades recreativas: caza y descanso, En el tercer grupo encontramos una exclamación. En el cuarto grupo de oraciones se hace 
referencia a la vida familiar en el campo, y por último (5) se alude al final del día, cuando muere el sol.

Mención aparte merece el uso del adverbio en este poema. Su análisis cobra sentido cuando lo relacionamos con los tipos de realidad configurados en el poema.

Existe una realidad poética positiva que cobra vida en el discurso de Alfius, "él" lírico. La realidad circunstancial de Alfius (más adelante veremos que es también la del "yo" lírico) por el contrario, es negativa. La designación de los tipos de realidad existentes toma un sólido fundamento en el uso de los adverbios. Obsérvese el siguiente fragmento:

"Non me Lucrina iuverint conchylia magisve rhombus aut scari... Non Afra avis descendat in ventrem meum, non attagen Ionicus..." (vv. 49 y 50, 53 y 54)

La presencia de adverbios negativos nos permite clasificar estos versos como parte de la realidad negativa, donde se coloca Alfius. Aquí se ubica también el "yo" lírico, quien cumple su función desde la realidad negativa.

El "yo" lírico, importante elemento del poema, hasta ahora ausente, cumple la función de apreciar la diferencia que existe entre la realidad negativa (circunstancial, verdadera para Alfius, "él" lírico) y la realidad positiva o hipotética contenida en el discurso de Alfius. Esta apreciación es la que produce la ironía, a su vez, el eje organizativo de todo el poema.

Hemos de observar también el uso de algunos nombres propios que configuran la realidad negativa: "Lucrina", "Afra avis", "attagen Ionicus". Estos constituyen parte de la realidad de Alfius y del "yo" lírico. Designan alimentos exóticos y difíciles de obtener, que desagradan (connotación negativa) en relación con las comidas sencillas que aparecen en la realidad positiva o hipotética.

Por último vamos a analizar un hecho: los primeros 33 épodos forman el discurso de Alfius, "él lírico. Los últimos dos épodos constituyen el discurso de otra persona, que hemos convenido en llamar "yo" lírico.

El poema constituye pues un largo dictus de 33 estrofas, seguido de un modus de dos. Quien enuncia el dictus es Alfius; el modus corresponde al "yo"lírico. Se pueden distinguir dos procesos de enunciación: $1^{\mathrm{O}}$ el de Alfius, $2^{0}$ el del "yo"lírico, que engloba al primero. Encontramos pues correspondencia con los tipos de realidad: la realidad positiva (hipotética) se configura en el dictus y el modus parte desde la realidad negativa (circunstancial).

Esta enunciación compleja caracteriza un "yo" lírico alejado de su enunciación por la subenunciación de Alfius, quien se convierte en sujeto de su propia enunciación y objeto de la enunciación del "yo" lírico. El "yo" lírico está por lo tanto considerablemente distanciado. Es fuertemente épico. porque relato otro discurso, y analítico porque califica la enunciación de Alfius y hace surgir la ironía. La presencia del "yo" lírico es indispensable: sin él no tendríamos poema, puesto que no existiría la enunciación de la ironía y por lo tanto no serían necesarias las primeras 33 estrofas. 

forma:

Estas observaciones nos permiten ampliar la organización del poema en la siguiente

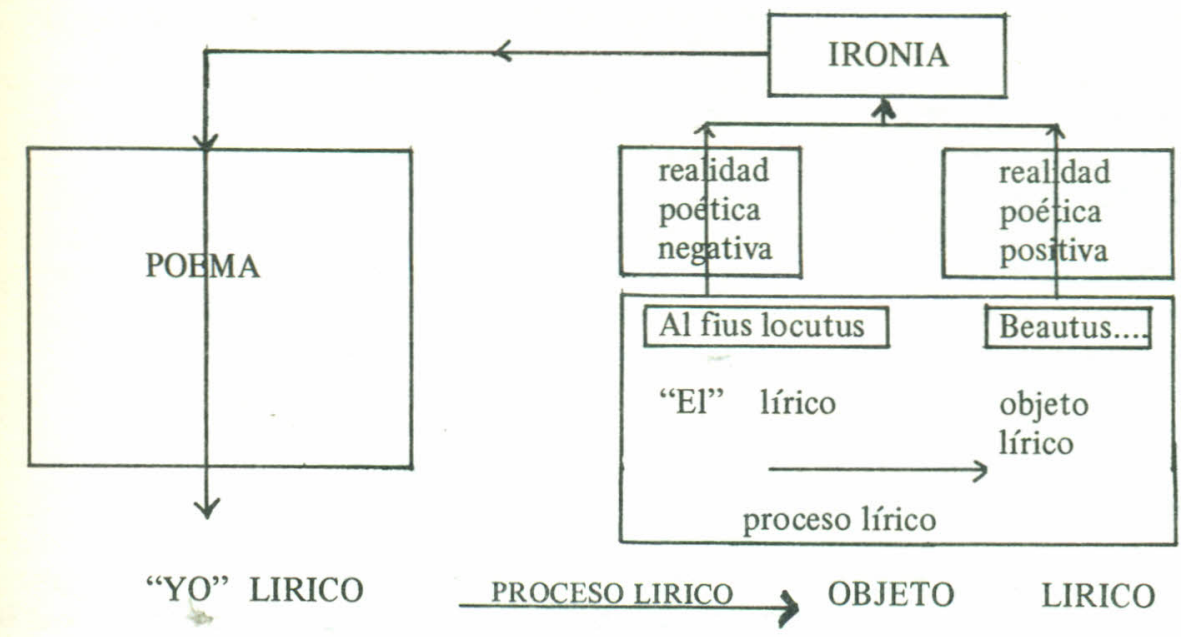

IV. Mundo representado y modo de representación $i$, ese mundo. El mundo representado en el poema, en relación con el cual es enunciado y enuncia a su vez el "yo"lírico, es el de la vida retirada, presentada como un "locus amoenus".

El poema nos es presentado en los primeros 33 épodos como la enunciación épico-lírica de un "él" lírico. Se presenta una serie de imágenes suscesivas. Estas nacen cuando un mismo espacio es enfocado desde distintos ángulos.

Algunas de estas imágenes llegan a constituirse en motivos, sobre todo cuando presentan una constitución semántica fija, el "locus amoenus". A continuación enumeramos una serie de imágenes, junto con la manera en que están determinadas y la realidad que configura cada imagen.

\section{IMAGEN}

1. "ille qui rura exercet ...ut..."

2. "nec excitatur..."

3. "nec horret..."

4. "forum vitat..."

5. "limina vitat..."

6. "propagine maritat..."

7. "prospectat greges..."

8. "feliciores inserit..."

9. "mella condit..."

10. "oves tondit..."

11. "gaudet decerpens..."

12. "libet iacere..."

13. "interim labuntur..."

14. "trudit acres..."

15. "tendit rara..."

16. "captat leporem..."

17. "quis non malarum..."

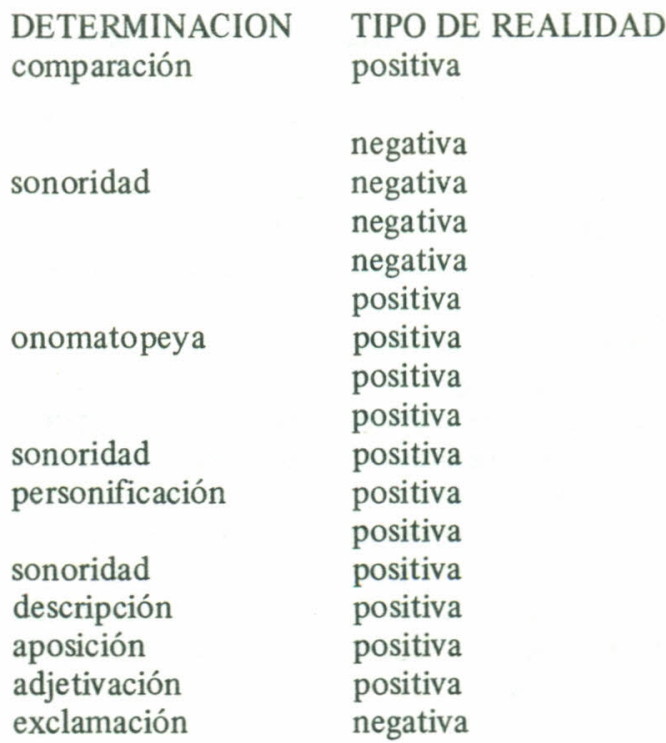




\begin{tabular}{|c|c|c|c|}
\hline 18. & "pudica mulier..." & símil & positiva \\
\hline 19. & "exstruat..." & descripción & positiva \\
\hline 20. & "siccet ubera..." & descripción & positiva \\
\hline 21. & "dapes apparet..." & & positiva \\
\hline 22. & "non me iuverint..." & & negativa \\
\hline 23. & "rhombus aut scari..." & oración condicional & negativa \\
\hline 24. & "non Afra avis descendat..." & nombre propio & negativa \\
\hline 25. & "non attagen Ionicus..." & nombre propio & negativa \\
\hline 26. & "quam lecta oliva..." & comparación & positiva \\
\hline 27. & "herba et malvae..." & comparación & positiva \\
\hline 28. & "agna caesa vel hoedus..." & comparación & positiva \\
\hline 29. & "iuvat videre oves..." & & positiva \\
\hline 30. & "iuvat videre boves..." & descripción & positiva \\
\hline 31. & "vernas circum Lares..." & aposición & positiva \\
\hline 32. & "iam iam futurus rusticus" & ironía & negativa \\
\hline
\end{tabular}

La correspondencia entre estrofa e imagen no es rigurosa pero sí regular en alto grado, y por lo tanto adquiere carácter significativo. Encuentra sentido en un paralelismo con la estrofa corta y el ritmo de compases cortos.

Esta presentación sucesiva de imágenes no se constituye en narración por dos razones. La primera es la temporalidad presente. No existe un referente pretérito: los verbos están todos en presente (con ciertas excepciones, vg. en el verso 49 un futuro relacionado con el presente). El orden cronológico se deduce del contexto semántico, cuando se describen las actividades agrícolas según su estación. Las estaciones se suceden dentro del poema, mientras se mantienen gramaticalmentel las formas de presente. Se logra así, en las primeras 33 estrofas, eliminar el transcurso del tiempo, suspendiéndolo.

La segunda razón es la forma en que se describe la naturaleza. No se trata de aproximarse a una circunstancia concreta, sino de emplear un esquema semántico fijo con elementos estereotipados que corresponden a ua norma de belleza definida. Podría hablarse de una naturaleza idealizada, que no intenta mimetizar una circunstancia específica.

La fuerza generadora del motivo se reafirma con la atemporalidad, lograda con base en el uso del presente. La organización del poema (dictus de 33 estrofas y modus de 2) refuerza las imágenes atemporales e idealizadas. Estas forman parte del discurso de un "él" lírico, Alfius, que configura una realidad poética positiva. A su vez esta realidad se define por oposición a la realidad poética negativa - circunstancia tanto de Alfius como del "yo" lírico..

V. El entorno del poema. La situación de Horacio.

En la época de Horacio, la pequeña propiedad no existía igual que en los primeros tiempos de la civilización romana. Los campesinos habían emigrado hacia las ciudades, y el oficio de agricultor había perdido prestigio. Las colonias suministraban todo lo necesario para el sostenimiento del imperio.

Sucede entonces que la forma de vida antigua y las características de la sociedad agraria - particularmente conservadora - se convierten en un ideal de vida, puesto que ya no existen. Las nuevas costumbres, el lujo, la influencia del Oriente, habían transformado la moral y las actitudes vitales.

Sin embargo, el estoicismo subyacente en la cultura romana, temperado por el epicureísmo, sostiene este ideal de la vida rústica y austera, de placeres simples y trabajo constante, ya tan alejado de la suntuosa y sofisticada sociedad imperial de la época de Horacio. El 'Beatus ille...' surge en este momento, y establece una correspondencia con el ideal de vida de esa época. 


$$
\mathrm{N} O \mathrm{~T} \text { A S }
$$

1. Wolfgang Kayser. Interpretación y análisis de la obra literaria. (Madrid: Ed. Gredos S.A., 1970), pp.315 y ss.

2. René Wellek y Austin Warren. Teoría literaria. (Madrid: Ed. Gredos, S.A., 1966) pp.193 y ss.

3. Kayser, op. cit., p.205.

\section{BIBLIOGRAFIA}

1. Horace. Odes et épodes. Tome I. Texte établi et traduit par F. Villeneuve. Paris: Societé d'edition "Les Belles Lettres", 1927.

2. Horatius Flaccus, Q. Publié par E. Sommer. Paris: Librairie Hachette et Cie., 1894.

3. Kayser, Wolfgang. Interpretación y análisis de la obra literaria. 4a. ed. rev. Versión española de María D. Mouton y V. García Yebra. (Biblioteca Románica Hispánica). Madrid: Ed. Gredos S.A., 1970.

4. Wellek, René y Warren, Austin. Teoria literaria. 4a. ed. Prólogo de Dámaso Alonso. Versión española de José María Gimeno. (Biblioteca Románica Hispánica). Madrid: Ed. Gredos, S.A., 1966. 